\title{
Classtalk System For Predicting And Visualizing Speech In Noise In Classrooms
}

\author{
Murray Hodgson \\ Dept. of Mechanical Engineering and School of Occupational and Environmental Health, \\ University of British Columbia, 3rd Floor 2203 East Mall, Vancouver, BC, Canada, V6T 1Z3 \\ hodgson@mech.ubc.ca
}

\section{INTRODUCTION}

The objective of the work reported here was to develop a classroom speech-intelligibility prediction tool, applicable to typical classrooms, which is accessible to non-specialist users. It was required to be simple, fast, accurate and interactive, running on standard PC computers. The system developed - a Windows system - is called ClassTalk.

\section{FUNCTIONALITY}

ClassTalk allows a classroom to be modeled, sound-field descriptors to be predicted, and for the classroom and predicted quantities to be visualized on the computer monitor. In real time, the user can 'walk-through' the classroom on the monitor, exploring the sound field and associated speech quality. Using ClassTalk, the user can define the physical and acoustical characteristics of a classroom and its noise sources. ClassTalk takes into account occupant sound absorption and student-activity noise, both crucial to the accurate prediction of classroom acoustics. The classroom floor-plan is visualized on the monitor, along with the speech- and noise-source positions, and a receiver icon indicating the receiver position. The user can 'walk-through' the classroom at will by moving the receiver icon. At every walk-through position, in real time, five outputs - speech level, background-noise level, signalto-noise level difference, Speech Transmission Index (STI) and speech intelligibility - are calculated and displayed. Contour maps of the five predicted quantities can be plotted. Also calculated and displayed are reverberation times for both the unoccupied (i.e., as designed by the architect) and occupied (i.e., as experienced by the occupants) classroom. The classroom floor-plan display can be printed, along with the input data, in the form of a one-page prediction report. The values of the five predicted quantities at the receivergrid positions can be exported to a file for further processing.

The input characteristics of the classroom that must be entered are its description, dimensions, sound-absorbing features, and the coordinates and sound-power levels of the sources. Student-activity noise can be considered or not, as desired. Sound-absorbing features include carpeting, acoustical treatment of the walls and ceilings, upholstered seating and students, who absorb propagating sound. Sources can be male or female speakers, three types of projector or ventilation outlets. At any time, the classroom data can be edited - for example, to introduce control measures. Control can be achieved by modifying the room geometry, adding surface absorption, and reducing ventilation-outlet and equipment output levels. The modified classroom and the new values of the five acoustical quantities are displayed. The classroom can be 'walked-through' with real-time update of the visual display. New noise contours can be drawn.

\section{PREDICTION MODELS}

Class Talk uses novel, simplified empirical models to predict total A-weighted speech levels $(S L A)$ and noise levels $B G N A$, due to ventilation (VNA) and student-activity ( $S A N A)$ noises, as well as $1000-\mathrm{Hz}$ early-decay times $(E D T 1)$. Noise levels at a receiver position are calculated by summing the contributions of the individual noise sources. Individual speech- and noise-level contributions are determined from the predicted sound-propagation curves describing the rate of decrease of levels with increasing distance from a source, as well as from their absolute levels. The empirical models were developed from a database of 'typical' university classrooms measured when unoccupied and occupied. These account for speaker voice level (and how it adapts to the prevailing acoustical conditions), noisesource output levels, classroom shape and absorption (including occupants), as well as student-activity noise, as they occur in real classrooms. Full details of the prediction models can be found elsewhere $[1,2,3]$.

\section{INPUT DATA}

\subsection{Sound-Absorbing Features}

Entering the extent of the sound-absorbing features in the classroom involves inputting the percentage of the side walls and of the ceiling covered with acoustical treatment, as well as the percentage floor area that is carpeted. Since students absorb sound, the number of students inside the classroom is specified; the resulting absorption is determined from the $1000-\mathrm{Hz}$ absorption per student [4]. Seating can be defined as hard or acoustically-absorbent upholstered seating. The total $1000-\mathrm{Hz}$ surface absorption coefficient is found by summing the contributions of the untreated and sound-absorbing surfaces [1]. 


\subsection{Speech and Noise Sources}

The typical ranges of total A-weighted output sound-power levels of male and female speakers were determined from published data [5]. Those of the four types of noise source overhead, slide and LCD projectors, and of ventilation outlets - were determined from extensive sound-intensity measurements [6]. From the ranges, values corresponding to four output levels (referred to as quiet, normal, raised and loud) were assigned.

\section{EXAMPLE PREDICTIONS}

Figure 1 shows ClassTalk prediction results for a large classroom, before and after treatment. Student-activity noise was not considered. The figures show contour maps of speech intelligibility (SIo), and the full ClassTalk visual displays, for the two cases. They include the unoccupied and occupied reverberation times, and the values of the predicted quantities at the walk-through position indicated by the square receiver icon.

The classroom has dimensions of $24 \mathrm{~m}$ by $22 \mathrm{~m}$ by $6 \mathrm{~m}$ high, and contains 400 occupants. Before treatment, it has non-absorptive seats, walls and ceiling; the floor is $80 \%$ carpeted. A female instructor, speaking in a normal voice, is located $2.5 \mathrm{~m}$ from the front wall. An overhead projector, with normal output level, is located near the instructor. An LCD projector, with normal output level, hangs from the ceiling in the middle of the classroom. Three ventilation outlets, with loud output levels, are located on one sidewall. Speech levels vary with distance from the instructor from 55 to $39 \mathrm{~dB}$. Noise levels vary from $49 \mathrm{~dB}$ near the noisy ventilation outlets, to $39 \mathrm{~dB}$ far from them. Signal-tonoise level differences vary from $12 \mathrm{~dB}$ near the instructor to $-9 \mathrm{~dB}$ near the ventilation outlets. Speech intelligibility varies from $94 \%$ ('good' quality) near the instructor to $39 \%$ ('bad' quality) near the vents. Reverberation times vary from 1.1 to $2.8 \mathrm{~s}$ in the unoccupied classroom, and from 0.6 to $1.7 \mathrm{~s}$ in the occupied classroom.
Acoustical treatment of this classroom aimed to reduce noise, and to control reverberation to near optimal values [7]. It consisted of HVAC noise control (reducing the ventilation outlets to 'normal' output levels), applying sound-absorptive materials to $50 \%$ of the ceiling and side walls, and installing sound-absorbing upholstered seating. After treatment, speech levels vary with distance from the instructor from 50 to $36 \mathrm{~dB}$ (reductions of 3 to $5 \mathrm{~dB}$ ). Noise levels vary from about $35 \mathrm{~dB}$ near the overhead and video projectors - now the dominant noise sources - to $28 \mathrm{~dB}$ far from noise sources (reductions of 10 to $13 \mathrm{~dB}$ ). Signal-tonoise level differences vary from $18 \mathrm{~dB}$ (an optimal value) near the instructor, to $6 \mathrm{~dB}$ under the video projector, and to $8 \mathrm{~dB}$ near the ventilation outlet farthest from the instructor (increases of 6 to $17 \mathrm{~dB}$ ). Speech intelligibility varies from 94 to $96 \%$ ('very-good' quality) throughout the room (increase of 3 to $55 \%$ ). Reverberation times vary from 0.6 to $0.8 \mathrm{~s}$ in the unoccupied classroom, and from 0.5 to $0.7 \mathrm{~s}$ in the occupied classroom. The sound absorption - in particular, the upholstered seating - has reduced the sensitivity of the reverberation times to occupancy.

\section{CONCLUSIONS}

ClassTalk achieves the objective of developing a classroom prediction tool that is accessible to the non-specialist. A demo version is available from www.flintbox.ca.

[1] M. R. Hodgson, J. Build. Acoust. 8(1) 1-14 (2001).

[2] M. R. Hodgson, R. Rempel and S. M. Kennedy, J. Acoust. Soc. Am. 105(1) 226-233 (1999).

[3] M. R. Hodgson, J. Acoust. Soc. Am. 112(2) 568-575 (2002)

[4] M. R. Hodgson, J. Acoust. Soc. Am. 106(4) 1810-1819 (1999).

[5] American National Standard Methods for Calculation of the Speech Intelligibility Index, ANSI S3.5-1997.

[6] R. Wang, Project report, U. British Columbia (2001).

[7] M. R. Hodgson and E.-M. Nosal, J. Acoust. Soc. Am. 111(2) 931-939 (2002).
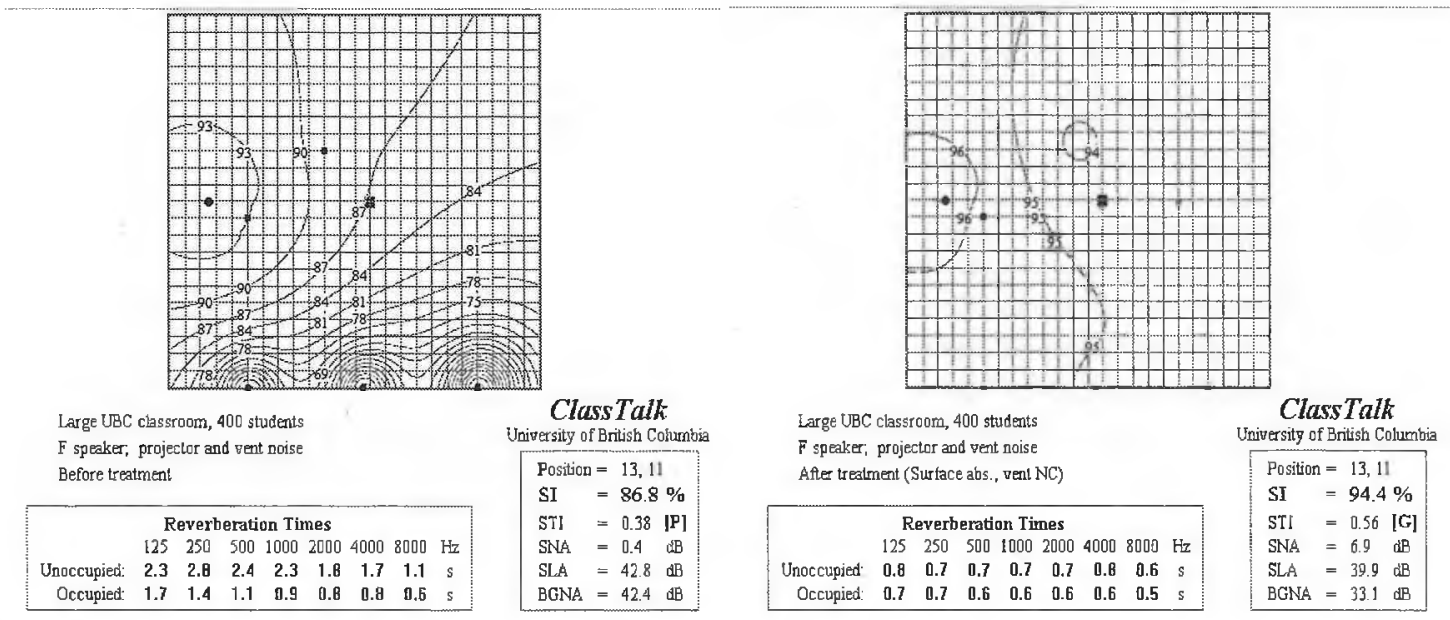

Figure 1. ClassTalk predicted sound-field and speech-quality descriptors for a large classroom before (left) and after (right) acoustical treatment. Classroom and treatment details are in the text. 